Revista de Economia Política, vol. 31, no 2 (122), pp. 283-304 abril-junho/2011

\title{
Para medir as desigualdades raciais no mercado de trabalho
}

\section{PEDRO C. CHADAREVIAN*}

Measuring racial inequalities in the labor market. How much racial inequality is there in Brazilian labor market? What has been the impact of the latest transformations in work relations on it? Can we compare the Brazilian situation to other countries? These questions don't have today an objective answer. This is due, mostly, to the absence of measures which could allow us to make long term and regional comparisons of different racial inequalities situations. Our proposal is to provide new indicators to evaluate racial inequalities in both the occupational and income structure in Brazil. Our results show that whites/non-whites gaps widened since the 1980s. They allow us to affirm, in addition, that racial inequalities are today worst in Brazil than in countries that adopted affirmative action laws to fight discrimination.

Keywords: racial inequalities; social-economic measures; labor market.

JEL Classification: I32; J71.

\section{APRESENTAÇÃO}

Os cientistas sociais são unânimes em constatar a existência de desigualdades raciais no mercado de trabalho no Brasil. As divergências surgem com respeito ao grau que o fenômeno assume na atualidade, bem como à sua evo-

\footnotetext{
* Doutor em Economia pela Universidade de Paris 3, Sorbonne Nouvelle, professor do curso de Economia da Universidade Federal de São Carlos (Campus Sorocaba). E-mail: pedro.chadarevian@gmail. com. Agradeço aos professores Maria Carolina Leme, Vladimir Ponczek e Luiz Carlos Bresser-Pereira pelos comentários inestimáveis dirigidos a uma versão prévia deste artigo, quando de sua apresentação nos Seminários de Pesquisa da EESP/FGV em junho de 2007. Sou grato, igualmente, a Larissa Cecília Domingues, minha orientanda e bolsista $\mathrm{CNPq}$ de iniciação científica, pela revisão final feita a esta versão do texto. Agradeço, enfim, às considerações preciosas dos pareceristas, que muito enriqueceram a minha visão sobre o tema abordado no artigo. Submetido: Julho 2008; Aprovado: Junho 2009.
} 
lução ao longo do tempo. Assim, questões centrais como o impacto das políticas públicas recentes sobre as desigualdades raciais seguem sem uma resposta concreta. Consequentemente, têm surgido propostas radicalmente distintas para combater o problema. É evidente que estas divergências se devem, em parte, ao posicionamento normativo do cientista social, variável conforme o contexto histórico, e conforme o conceito de justiça distributiva em que baseia sua abordagem da realidade social.

A partir de um resgate histórico das tentativas, no pensamento social e econômico, de medir as desigualdades econômicas - em especial as que opõem os grupos étnico-raciais - procuraremos fornecer uma metodologia alternativa, superando algumas das dificuldades hoje existentes. Estas são principalmente de duas ordens. Em primeiro lugar, com relação à desigualdade racial na estrutura ocupacional do mercado de trabalho, os indicadores propostos - como o índice de dissimilaridade — pecam por não possibilitar comparações ao longo do tempo e entre países ou regiões diferentes. Enfrentam também o problema de agregar de forma objetiva, em um único indicador, ocupações extremamente diferentes. Podem, além disso, produzir resultados ambíguos, dificultando a sua aplicação à realidade.

Em segundo lugar, e referindo-se mais especificamente ao terreno do economista, nota-se uma dificuldade metodológica na contribuição para se medir a desigualdade racial de rendimentos. As medidas hoje dominantes na literatura derivam de uma fundamentação neoclássica do funcionamento da economia baseadas na teoria do capital humano, segundo a qual os diferenciais de salários entre brancos e não brancos se devem às diferentes oportunidades de “acumular conhecimento" ${ }^{1}$. Estas são, porém, de pouca praticidade, já que não resultam em um indicador comparável do quadro de desigualdade racial. Trata-se, na realidade, de medidas normativas, como as chamou Amartya Sen, ou seja, medidas orientadas por uma concepção particular do funcionamento da economia, como veremos em detalhe a seguir. No que se refere às medidas positivas, pode-se dizer que a orientação teórica do autor não influencia diretamente a mecânica do indicador ${ }^{2}$. Neste campo da abordagem positiva da desiguadade racial, o economista tem usado, em geral, o "income ratio", que é dado pela simples proporção da renda mediana dos não brancos em relação

\footnotetext{
${ }^{1}$ Dentre os precursores desta interpretação, consultar Phelps (1972) e Becker (1971). Arrow (1972) propôs uma visão neoclássica alternativa, que não exerce grande influência neste debate.

${ }^{2}$ Assim, por exemplo, ainda que Gini se inscreva em uma tradição heterodoxa, ao utilizarmos o seu indicador de concentração para medir a desigualdade não estamos endossando a sua concepção particular, corporativista, de funcionamento do mercado. Muito diferente é a opção pelo instrumental neoclássico para medir a desigualdade, quando, ao utilizá-lo, temos de concordar com o pressuposto da igualdade entre salários e produtividade marginal. É esta contraposição sutil que leva Sen (1997, p. 24) a afirmar que, apesar de não haver uma fronteira clara que separe indicadores positivos de normativos, a distinção entre eles não deixa de ser perfeitamente útil e necessária para uma avaliação comparativa das medidas de desiguadade.
} 
à dos brancos. Apesar da facilidade de manipulação, este indicador pouco nos informa sobre os extremos da distribuição, podendo também levar a interpretações ambíguas.

O primeiro dos indicadores que propomos aqui, que chamamos de índice de hierarquização racial, mede a desigualdade na incorporação de brancos e não brancos ${ }^{3}$ à elite ocupacional urbana de um país, dada pelas categorias de empregadores, administradores, gerentes e profissionais liberais. Os resultados a que chegamos, baseados em dados da PNAD dos anos de 1982 e 2003, mostraram um alto nível de desigualdade racial na estrutura ocupacional do Brasil, e uma piora em relação à situação de vinte anos atrás. Além disso, realizamos uma comparação internacional na qual o Brasil apresenta o pior quadro neste quesito, atrás de França, Estados Unidos e Grã-Bretanha. O segundo indicador visa mensurar os diferenciais de rendimentos no mercado de trabalho entre grupos raciais. Este indicador, que batizamos de coeficiente de desigualdade racial, utiliza uma metodologia semelhante à do indicador de Gini. Ao aplicá-lo aos dados, constatamos igualmente a existência de importantes desigualdades raciais de renda no Brasil.

\section{OS ÍNDICES DE DESIGUALDADE EM SEU DEVIDO CONTEXTO}

$\mathrm{Na}$ ciência econômica, a profusão de concepções de justiça distributiva dá origem a igual número de propostas de medir as desigualdades. Nos primeiros cem anos após o nascimento da economia moderna no século XVII, estas propostas ficaram restritas ao nível subjetivo da comparação de utilidades ${ }^{4}$. Em seguida, com o desenvolvimento do pensamento crítico nos séculos XVIII e XIX, começaram a esboçar-se novas formas de encarar o problema. No princípio, predominaram abordagens exclusivamente empíricas da questão, baseadas na simples constatação da concentração dos rendimentos e da propriedade nas mãos de uma pequena parcela da população ${ }^{5}$. O embate se dava entre os que procuravam demonstrar o caráter inerente da desigualdade na sociedade capitalista, e os que tentavam relativizá-lo. Foi necessária a intervenção de um matemático (e economista), Corrado Gini, nos anos 1920, para "resolver" este conflito, propondo uma medida técnica, e livre portanto de interferências

\footnotetext{
${ }^{3}$ Neste artigo seguiremos a tradição dos estudos sobre desigualdade racial no Brasil e consideraremos o grupo social dos não brancos como aquele que reúne as categorias censitárias "pretos" e "pardos" do IBGE. Exlcuiremos "indígenas" e "amarelos" da análise, por estarem sujeitos a uma lógica particular de discriminação.

${ }^{4}$ Isto fica claro com um exame detalhado da obra dos grandes economistas clássicos, como Smith, Ricardo ou Malthus. Ver, por exemplo, Verburg (2000).

${ }^{5}$ Consultar, entre outros, Lafargue (2004). A proposta mais avançada de medida de desigualdade do período foi, certamente, a taxa de exploração econômica de Marx. Para uma aplicação, ver Gouverneur (1998, p. 67).
} 
explícitas das concepções de justiça distributiva. E, ainda que a interpretação do nível e da evolução deste indicador esteja sujeita à orientação ideológica do cientista social que a utiliza, ele continua sendo nos dias de hoje uma referência para os estudos da desigualdade ${ }^{6}$.

No Brasil, a questão da desigualdade só viria a suscitar um verdadeiro debate nas ciências sociais quando, a finais dos anos 1960, constata-se que o modelo de desenvolvimento promovido pelos militares dava lugar a um rápido processo de concentração de renda e de riquezas. Em seguida, os anos 1980 serão descritos pelos críticos como a "década perdida"; e não apenas pelas pífias taxas de crescimento econômico, mas, sobretudo, pela expansão do fenômeno da desigualdade. $\mathrm{Na}$ atual conjuntura, uma série de estudos tem procurado vincular a manutenção destas desigualdades com a consolidação das políticas econômicas de cunho liberal no país.

\section{A breve história dos índices de desigualdade racial}

Se, como dizíamos na apresentação, há consenso a respeito da existência de desigualdades raciais no mercado de trabalho no Brasil de hoje, o mesmo não se pode dizer do nível desta desigualdade, ou como ela vem evoluindo ao longo dos últimos anos. Para muitos, o racismo e a discriminação teriam aumentado no Brasil ${ }^{7}$. Os economistas de orientação neoclássica, por outro lado, constatam a existência de discriminação racial no mercado de trabalho, mas ressaltam, invariavelmente, a sua reduzida influência nas oportunidades econômicas dos indivíduos, como veremos a seguir.

Evidentemente, o que está por trás destas interpretações contraditórias é a forma como se analisa o impacto do racismo no mercado de trabalho. Mas não apenas isto. A falta de indicadores consistentes capazes de sintetizar um quadro de discriminação racial e compará-lo a situações distantes no tempo e no espaço é também parte do problema. Assim, ao contrário do que ocorre com outras formas de desigualdade - como na distribuição de renda no mercado de trabalho (índice de Gini) ${ }^{8}$, ou na de bem-estar social entre as sociedades (índice de desenvolvimento humano, IDH) — não é possível atualmente medir de forma adequada e simplificada a distância socioeconômica que separa brancos e não brancos nos diferentes países.

$\mathrm{Na}$ verdade, os economistas neoclássicos mantêm a hegemonia nesta discussão, sugerindo como medida da distância entre grupos sociais a compara-

\footnotetext{
${ }^{6}$ De acordo com Sen (1997, pp. 32-33), o coeficiente de Gini ainda se apresenta como o melhor indicador positivo de desigualdade, apesar de problemas identificados pelo autor na sensibilidade da direção de transferências de renda em uma dada distribuição.

${ }^{7}$ Consultar, entre outros, Gorender (2000), Telles (2003) e Paixão (2004).

${ }^{8}$ A literatura econômica da desigualdade tem se dedicado quase que exclusivamente ao problema da desigualdade de renda. Para uma síntese ver, entre outros, Silber (1999) e Sen (1997).
} 
ção entre salários de indivíduos "igualmente produtivos". O indicador neoclássico pode assumir diferentes formas, desde o simples resíduo ou coeficientes da regressão de uma função de rendimentos ${ }^{9}$, passando pela medida de decomposição de salários de Blinder-Oaxaca ${ }^{10}$, até propostas recentes de indicador decomposto de desigualdade salarial ${ }^{11}$. Há dois problemas com estas medidas de desigualdade racial e sexual. O primeiro deles é que, em uma regressão, a comparação resume-se à média de salários, negligenciando a estrutura da distribuição de rendimentos em uma economia. $\mathrm{O}$ segundo problema é que não são indicadores isentos, na medida em que estão baseados em uma concepção individualista e meritocrática da função de bem-estar social. Para os neoclássicos, é preciso que se respeite o axioma segundo o qual só há desigualdade quando o salário não corresponde ao esforço despendido no processo produtivo. Segundo este raciocínio, em uma sociedade ideal a produtividade individual deve ser equivalente ao salário, a menos que "imperfeições de mercado" atuem em sentido contrário, distribuindo de forma desigual as oportunidades. Ou seja, como a desigualdade em si é perfeitamente justificável, apenas a desigualdade de "oportunidades" será objeto de análise dos neoclássicos.

$\mathrm{Na}$ literatura crítica, o sociólogo Du Bois é o pioneiro nos estudos empíricos das desigualdades raciais no mercado de trabalho. Ao rejeitar a valor científico dos estudos das diferenças biológicas e culturais entre grupos raciais, $o$ autor trouxe a discussão para o campo socioeconômico, reorientando o uso da estatística, que passa assim de um instrumento de legitimação do racismo, a um meio de criticá-lo. O autor chamou a atenção, já em 1899, para a representatividade extremamente desigual nas elites e a concentração de não brancos em serviços domésticos, manuais e na pobreza, nos EUA ${ }^{12}$. Um pouco mais tarde, Myrdal (1942, p. 692) faria uma importante contribuição neste sentido, ao propor uma representação gráfica inovadora da desigualdade racial na estrutura de classes. O autor desenha, em um quadro dividido em três segmentos representando três níveis de status social (baixo, médio e alto), uma curva com a proporção relativa de não brancos. Infelizmente, Myrdal não vai além desta sugestão metodológica, e não coloca em prática o indicador que

\footnotetext{
${ }^{9}$ Ver, entre outros, Paes de Barros \& Mendonça (1996); Cavalieri \& Fernandes (1998).

${ }^{10}$ Para exemplos recentes da aplicação do método de decomposição de salários de Blinder-Oaxaca, veja-se, entre outros, Lovell (2000); Campanante et al. (2004); Reis e Crespo (2005).

${ }^{11}$ A referência desta última proposta está em Cowell e Jenkins (1995). O resultado a que chegam os autores não traz nenhuma novidade, porém, às análises neoclássicas, pois suas conclusões sugerem que a desigualdade de renda entre brancos e negros não é importante para explicar a desigualdade geral da economia. E que, portanto, a origem do problema racial estaria na desigualdade de renda da população negra, determinada pela distribuição desigual de oportunidades.

${ }^{12}$ Veja-se, por exemplo, o interessante o cálculo que realiza o autor da participação dos negros de Filadélfia em quatro classes selecionadas, comparando com a situação da população da cidade de Londres (Du Bois, 1975, p. 171).
} 
implicitamente propôs - o que poderia ter sido feito por meio do cálculo da razão das áreas de seu gráfico.

De fato, se no pensamento crítico o recurso à análise empírica das desigualdades raciais sempre esteve presente, poucas foram as tentativas de sintetizá-las por meio de um indicador. Há, contudo, algumas exceções que convém avaliar. Comecemos pelos trabalhos de dois economistas norte-americanos, que têm se destacado ultimamente na crítica do problema racial em seu país. No primeiro deles, Conrad (1993) adaptou o chamado índice de Atkinson para medir a evolução da desigualdade racial na distribuição de renda nos EUA entre os anos 1950 e 1980. Em resumo, seu indicador permite que uma transferência de renda no extremo inferior da distribuição seja preferível a uma transferência no extremo superior. Segundo os cálculos da autora, houve uma tendência de piora na desigualdade racial nos anos 1970 e 1980, revertendo os ganhos do período anterior. Algumas críticas podem ser, no entanto, dirigidas à metodologia de cálculo do índice de Atkinson. Em primeiro lugar, ele exige uma escolha arbitrária a respeito da ponderação que se deve dar aos movimentos de transferência de renda. Em segundo lugar, e como reconhece a própria Conrad, a medida se baseia em uma concepção individualista da função de bem-estar social. E mais: como o índice não é propriamente um indicador de desigualdade de renda, mas um indicador do impacto sobre o bem-estar (dado pela soma das utilidades individuais) de uma variação na renda, ele está sujeito à relação existente entre renda e utilidades. Como bem demonstra Sen (1999, p. 145), em uma função que prevê rendimentos decrescentes na utilidade marginal dado um aumento na renda (hipótese factível com a teoria neoclássica dos salários), o índice de Atkinson pode levar a resultados contraditórios, o que leva o autor a descartá-lo como uma medida eficiente da análise da desigualdade no mercado de trabalho.

Outro estudo econômico de orientação crítica realizado nos EUA sobre o tema é, na realidade, uma sugestão de adaptação do chamado indicador de Theil para o cálculo da desigualdade racial (Darity Jr. e Deshpande, 2000). $\mathrm{Na}$ decomposição feita pelos autores, o indicador é dado pela soma de dois componentes: a desigualdade de renda entre grupos raciais, e no interior de um dos grupos. Como eles mesmos suspeitam, isto pode levar a resultados ambíguos e de complexa interpretação. Assim, em um caso hipotético com redução na desigualdade no interior do grupo (não brancos) maior que na desigualdade entre os grupos (brancos e não brancos), o indicador apontaria para uma diminuição na desigualdade racial geral; o que não deixa de ser um paradoxo.

Já no campo da desigualdade ocupacional entre grupos sociais (gênero e raça) a contribuição mais importante foi, aparentemente, a de Susan Carlson (1992). A partir de uma crítica ao índice de dissimilaridade, que veremos em detalhe mais abaixo, ela propõe o uso de um indicador adaptado do coeficiente de concentração de Gini para medir o fenômeno. Seu indicador permite tanto comparações internacionais como comparações ao longo do tempo, pois 
é ponderado em relação à proporção dos grupos raciais na população. As únicas dificuldades associadas à sua utilização são, de um lado, o efeito marginal diferenciado segundo a proporção de não brancos no país/região; e, de outro lado, a sensibilidade ao tamanho da amostra, exigindo um número de categorias ocupacionais bastante elevado. Além disso, é preciso ressaltar um importante problema de ordenação das ocupações que surge no momento de composição do índice. Ou seja, a questão que se coloca é: como ranquear objetivamente as ocupações no mercado de trabalho? Se sabemos que a distância que separa ricos e pobres em termos monetários é perfeitamente mensurável, esta distância em termos ocupacionais não é tão clara. É evidente que um gerente está acima, em termos hierárquicos, de um trabalhador da construção civil; mas quão acima ele está, é uma questão de difícil resposta. Carlson, em uma tentativa de superar este problema, utiliza a renda e a educação do trabalhador para quantificar estas distâncias; o que não deixa de expressar o próprio limite do indicador, na medida em que este procedimento o transforma basicamente em uma medida de desigualdade de rendimentos, e não mais de ocupações no mercado de trabalho.

\section{O debate sobre a mensuração da desigualdade racial no Brasil}

No Brasil, os primeiros estudos empíricos sobre a desigualdade racial no mercado de trabalho datam do pós-Segunda Guerra Mundial. Eles confrontaram, em linhas gerais, duas correntes que se baseavam em concepções distintas do fenômeno das desigualdades: uma que acreditava no funcionamento meritocrático do mercado como o principal fator de ascensão social dos não brancos; e outra que sustentava a existência de barreiras sociais e raciais. Ambas procuraram fundamentar suas hipóteses em uma análise de dados. Representando este segundo grupo de cientistas sociais, Fernandes (1972) tem como ponto de partida o estudo da "flagrante desigualdade que separa o negro do branco na estrutura profissional em São Paulo" (p. 62), e propõe, claramente inspirado por Du Bois, dois indicadores para corroborar sua hipótese. O primeiro é a proporção de trabalhadoras domésticas, e o segundo é a proporção relativa de empregadores - sempre em relação ao conjunto da população não branca. Os resultados comprovam suas expectativas, e destacam que a desproporção entre brancos e não brancos no topo da pirâmide atingia de três a oito vezes, dependendo da região. Era um primeiro esboço de indicador de desigualdade racial para o Brasil.

Nos anos 1970, Hasenbalg (1979), a partir de uma concepção original de Amaury de Souza, desenvolveu um indicador para medir a desigualdade racial em grupos de ocupação do mercado de trabalho, produzindo talvez uma das contribuições mais aprofundadas sobre o tema. O "indicador de concentração", como o chamou o autor, tem a vantagem de ser de simples manipulação, e se apresenta segundo a equação abaixo: 


$$
\mathrm{IC}=\frac{\left(\mathrm{a}-\mathrm{a}^{\prime}\right)}{\left(\mathrm{a}+\mathrm{a}^{\prime}\right)}
$$

Sendo a a proporção da população não branca em uma dada ocupação, e a' a proporção de brancos na mesma ocupação. Assim, quando as proporções forem equivalentes, o indicador será igual a zero; e, quanto mais desigual a composição racial, mais próximo de - 1 ele estará. Os cálculos do autor demonstram um quadro de forte desigualdade para o ano de 1950, principalmente nas categorias mais elevadas do mercado de trabalho (p. 177). Este índice, apesar dos resultados aparentemente consistentes, possui, porém, alguns problemas ligados à sua especificação em uma função de desigualdade racial de retornos decrescentes à medida que se aumenta a proporção de não brancos na elite ocupacional. Nós retomaremos esta questão em detalhes na próxima seção do artigo.

Diversos autores e organizações internacionais, ignorando esta contribuição, têm procurado aplicar um indicador mais simplificado para medir a desigualdade racial na estrutura de ocupações, comumente chamado na literatura de índice de dissimilaridade ou de segregação ocupacional. Sua forma de cálculo pode ser representada através da fórmula seguinte, onde o índice i representa as diferentes ocupações no mercado de trabalho:

$$
\mathrm{ID}=\sum_{\mathrm{i}=0}^{n}\left[\frac{\left|\mathrm{a}_{\mathrm{i}}-\mathrm{a}_{\mathrm{i}}^{\prime}\right|}{2}\right]
$$

Ocorre que estas novas análises, ao não discriminarem as classes no mercado de trabalho, chegam a resultados ambíguos, já que não se procura calcular o impacto da situação nos extremos da distribuição sobre o resultado agregado $^{13}$. Este é, por exemplo, o método de cálculo de organismos internacionais como o PNUD (2005), que aponta para uma redução na segregação ocupacional por raça no Brasil nos últimos vinte anos. No entanto, é difícil avaliar, com base neste indicador, se esta queda se deve a uma melhora na proporção de não brancos na elite, ou se está ligada a uma mera acomodação em posições intermediárias da estrutura ocupacional.

Houve, é verdade, uma tentativa de resolver este problema na literatura, em que se procurou incluir o efeito da hierarquização das ocupações no mercado de trabalho (Fosset, 1986). Porém, a principal dificuldade ligada ao indicador de dissimilaridade é que ele não leva em consideração a pro-

\footnotetext{
${ }^{13}$ Para aplicações deste indicador à situação brasileira, veja-se: Dos Santos (1998, p. 114); Oliveira e Miranda-Ribeiro (1998); Lovell (2000). Uma adaptação deste indicador também foi feita para se medir a segregação racial por zona de habitação nas grandes metrópoles brasileiras, mostrando um grau elevado de desigualdade. Ver Telles (1992).
} 
porção de brancos e não brancos na população geral. Suponhamos, para simplificar, um mercado de trabalho com uma única ocupação, cuja proporção de não brancos equivale a um terço da proporção de brancos. $\mathrm{O}$ valor do índice de dissimilaridade é o mesmo nessa situação e em uma situação de melhora relativa de não brancos, por exemplo quando dobra a proporção de brancos e quadruplica a de não brancos naquela ocupação. Isto mostra a impossibilidade de comparações no tempo e espaço de quadros de desigualdade racial.

Convém registrar também a prática recente de se calcular indicadores de desigualdade - como o de Gini ou o de Theil — para a distribuição de renda de não brancos no Brasil. Este procedimento, por mais nobre que seja a sua intenção, não nos informa nada sobre a desigualdade racial de uma economia, apenas confirma o óbvio: que a distribuição de rendimentos no Brasil é mais concentrada entre brancos que entre não brancos, já que os últimos não conseguem penetrar nas faixas de renda mais altas do mercado de trabalho ${ }^{14}$.

Destaquemos, por fim, estudos que têm promovido a desagregação por grupo étnico-racial do Índice de Desenvolvimento Humano (IDH), com o objetivo de produzir um instrumental alternativo à análise das desigualdades. Uma aplicação desta metodologia para o caso brasileiro revelou que a população negra e mestiça situa-se em um nível de vida semelhante ao de países da África Central, e que, no Brasil, a diferença de qualidade de vida entre brancos e não brancos é bem maior do que a observada nos Estados Unidos (Paixão, 2004). Algumas ressalvas devem, contudo, ser feitas à metodologia de cálculo deste indicador. Em primeiro lugar, pode-se criticar a escolha das variáveis que compõem o índice - por que não outras medidas de renda, em lugar da renda per capita, por exemplo; ou de saúde, como o número de mortes violentas? Além disso, os valores máximos do índice, calculado pelo PNUD, são definidos de acordo com princípios normativos previamente estipulados (Destremau e Salama, 2002).

\section{UMA MEDIDA DO GRAU DE HIERARQUIZAÇÃO RACIAL NA ECONOMIA}

A abordagem neoclássica da desigualdade racial, dominante atualmente nos estudos quantitativos da discriminação, parte do pressuposto segundo o qual apenas as diferenças salariais que persistem entre indivíduos igualmente produtivos são resultantes de discriminação. Este pressuposto, fundamentado

${ }^{14}$ Ver, por exemplo, Henriques (2001, p. 22). 
em uma concepção muito particular da origem das desigualdades e do funcionamento do mercado de trabalho, torna enviesada e normativa a análise quantitativa das desigualdades raciais. Nossa proposta inspira-se, por outro lado, na tradição positiva da análise quantitativa da desigualdade social e racial. Neste sentido, não nos preocuparemos tanto em entender as possíveis fontes da desigualdade racial, e sim em medi-la da maneira mais simples e direta possível, livre da influência das diferentes concepções teóricas existentes. Na perspectiva crítica da análise da discriminação, a permanência de um elevado grau de desigualdade racial no mercado de trabalho é suficiente para se constatar a existência de racismo, definido como o processo que determina a hierarquização racial em uma economia, por meio da atuação de mecanismos de discriminação, como a divisão racial do trabalho ou a discriminação salarial exercidas contra a população não branca ${ }^{15}$.

Neste segmento gostaríamos, assim, de propor, com base em estatísticas disponíveis em diferentes países, a elaboração de um indicador alternativo da desigualdade racial na estrutura ocupacional do mercado de trabalho. A intenção é que este indicador se apresente como uma medida que seja capaz de sintetizar o grau de hierarquização racial da força de trabalho. A informação básica para este indicador será a diferença observada na composição racial da elite ocupacional no mercado de trabalho. Uma elevada proporção de brancos, relativa à de não brancos, em ocupações-chave da vida profissional ${ }^{16}$, será considerada como uma situação indesejável do ponto de vista do ideal de igualdade racial. Quanto maior a distância entre brancos e não brancos nas taxas de participação na elite ocupacional, maior o quadro de hierarquização racial. Pode, a princípio, parecer tratar-se de um reducionismo; mas a ausência de não brancos em cargos de direção e de altos salários é sempre apontada como um dos sinais mais evidentes da existência de discriminação e racismo em uma sociedade. Além disso, é nesta faixa da estrutura ocupacional, formada pelos administradores, gerentes e profissionais liberais, que se encontram as classes que mais se aproximam da propriedade dos meios de produção (e de informação), e que garantem a reprodução material (e ideológica) de uma sociedade capitalista.

Como dizíamos, a variável mais importante de nosso cálculo será a proporção relativa de não brancos e brancos presentes na elite econômica de um país ou região. Esta proporção será medida pela soma dos grupos ocupacionais referentes à direção, administração e profissionais liberais e científicos. A vantagem é que este dado está disponível em diversos países, e as estatísticas

\footnotetext{
${ }^{15}$ Veja-se, por exemplo, Balibar \& Wallerstein (1988), Gorender (2000), e Leiman (1993).

${ }^{16}$ Para facilitar as comparações, considerou-se como elite ocupacional os dois maiores níveis hierárquicos da tipologia do IBGE, ou seja, "dirigentes em geral” e "profissionais das ciências e das artes".
} 
do mercado de trabalho respeitam em geral a convenção internacional de codificação de ocupações ${ }^{17}$. A situação ideal é atingida quando as proporções para brancos e não brancos se igualarem, independentemente da distribuição de renda. A equação abaixo descreve o indicador proposto:

$$
\mathrm{IHR}=100-\frac{\left(\mathrm{P}_{\mathrm{b}}-\mathrm{P}_{\mathrm{n}}\right)}{\mathrm{P}_{\mathrm{b}}} \times 100
$$

Assim, quando a proporção de não brancos $\left(\mathrm{P}_{\mathrm{n}}\right)$ na elite for de zero, $\mathrm{o}$ indicador será igual a zero. Quando ela for igual à dos brancos $\left(\mathrm{P}_{\mathrm{b}}\right)$, o indicador valerá 100. A função acima descrita assume, na realidade, a forma de uma linha reta. Ou seja, o coeficiente de desigualdade vai se aproximando de 100 de maneira linear.

Já a função que descreve o indicador de concentração de Hasenbalg (IC), ao contrário da nossa, apresenta impactos marginais decrescentes a aumentos relativos na participação de não brancos na elite, o que desrespeita uma propriedade fundamental dos indicadores de desigualdade ${ }^{18}$, na medida em que variações no início da distribuição contribuem mais para a igualdade do que variações nos últimos segmentos. Em outras palavras, o IC tende a 100 de maneira muito mais rápida que o IHR, sem que haja nenhuma hipótese razoável para sustentar este raciocínio. A menos que se adote uma posição normativa pela qual políticas de combate à desigualdade racial são tanto mais preferíveis quanto maior é a distância que separa brancos de não brancos, o que não parece sustentável do ponto de vista ético.

Em comparação ao índice de concentração de Hasenbalg, o índice de hierarquização racial (IHR) que desenvolvemos tem a vantagem de não subestimar o quadro de desigualdade racial, e traz como resultado um número que tem uma contrapartida real, ou seja, a porcentagem de desigualdade racial na elite em um dado país. Além disso, dá pesos iguais a variações em diferentes situações de desigualdade racial nas elites. Na prática, a adoção desta metodologia implica que um nível dado de desigualdade racial na elite importa menos que o caminho efetivamente percorrido para se atingir um resultado de perfeita igualdade.

Com base nestas informações, podemos agora aplicar nosso indicador para estimar situações de desigualdade racial em diferentes épocas e países; informações que resumimos na tabela a seguir.

\footnotetext{
${ }^{17}$ As estatísticas sobre pobreza, por outro lado, envolvem invariavelmente uma abordagem normativa da questão, na medida em que sua avaliação depende de parâmetros subjetivos e variáveis de acordo com a época e o país.

${ }^{18}$ Trata-se do princípio de Dalton. Ver Ray (1998, p. 177).
} 
Tabela 1: Índice de hierarquização racial (IHR), para países e anos selecionados*

\begin{tabular}{|c|c|c|c|}
\hline País & $\begin{array}{c}\text { Elite } \\
\text { branca }\end{array}$ & $\begin{array}{c}\text { Elite } \\
\text { não branca }\end{array}$ & IHR \\
\hline Pior situação & $\mathrm{n}$ & 0,0 & 0,0 \\
\hline \multicolumn{4}{|l|}{ Brasil } \\
\hline Escravidão & 3,0 & 0,1 & 3,3 \\
\hline $1930^{* *}$ & 7,0 & 1,0 & 14,3 \\
\hline 1950 & 9,8 & 3,6 & 36,7 \\
\hline 1982 & 14,1 & 5,6 & 39,7 \\
\hline 2003 & 16,1 & 5,9 & 36,6 \\
\hline \multicolumn{4}{|l|}{ França*** } \\
\hline 1998 & 33,7 & 14,1 & 41,8 \\
\hline \multicolumn{4}{|l|}{$E \cup A^{* * * *}$} \\
\hline 1910 & 12,2 & 2,2 & 18,0 \\
\hline 1950 & 18,4 & 5,4 & 29,3 \\
\hline 1985 & 28,1 & 17,2 & 61,2 \\
\hline 2000 & 32,6 & 19,9 & 61,0 \\
\hline \multicolumn{4}{|l|}{ Grã-Bretanha } \\
\hline 2004 & 27,2 & 23,7 & 87,1 \\
\hline Igualdade & $\mathrm{n}$ & $\mathrm{n}$ & 100,0 \\
\hline
\end{tabular}

A tabela nos mostra que, em países tão diferentes quanto Brasil, EUA, França ou Grã-Bretanha (GB), o acesso a posições na elite econômica continua sendo desigual em relação à origem étnico-racial da pessoa. Por outro lado, se, de uma forma geral, em todos os países listados, a conjuntura atual se distancia muito de uma situação de segregação total ou escravidão, é evidente que há ainda um bom caminho a percorrer para se atingir a igualdade perfeita na composição racial das elites. Este caminho pode ser mais ou menos longo, dependendo do país. O país com o melhor resultado em nossa análise é a GB, seguida de longe pelos EUA. Bem mais abaixo aparecem França e Brasil. A tabela deve ser lida da seguinte maneira: o Brasil percorreu $36,6 \%$ do ideal de igualdade racial até o momento atual, a França $41,8 \%$, os EUA $61,0 \%$, e a GB $87,1 \%$.

Os dados estimados para a escravidão no Brasil se baseiam em diferentes estudos que atestam a presença de uma elevada população negra e mulata liberta no período, mais perceptível após a independência do país. Uma parte certamente muito reduzida - destes negros conseguiu ascender na estrutura social (apesar da segregação oficial que limitava o acesso a determinadas funções do setor público), atingindo setores da elite econômica não proprietária e urbana, como relata, por exemplo, Freyre ([1933] 2003). Gorender (1991) nos 
dá uma pista importante quando descreve que, nas eleições para deputado de 1884 , dos trinta candidatos, um era "de cor" - ou seja, uma proporção de $3,3 \%$. Por outro lado, negros e mestiços pareciam totalmente excluídos da classe dos proprietários rurais, em uma época de escassa urbanização. Considerando-se ainda que os não brancos eram $70 \%$ da população no século XIX, e que a elite total do país era composta de $1 \%$ do total dos brasileiros, podemos estimar que a proporção de não brancos na elite fosse próxima a $0,1 \%$.

É preciso ainda assinalar uma importante singularidade ao mesmo tempo histórica e demográfica nas relações raciais dos países europeus. A população não branca nestes países é, em geral, originária de antigas colônias, e sua imigração à Europa atendia às necessidades de uma economia em expansão no pós-guerra. Os dados que analisamos se referem em geral à segunda geração daqueles imigrantes, portanto já beneficiários da nacionalidade europeia. As semelhanças nestes aspectos entre França e Inglaterra nos levam a buscar em outros fatores a origem da diferença observada em seus IHR.

Temos, na realidade, quatro casos representativos de dois modelos distintos de gestão política do problema racial: o modelo intervencionista (na GB e EUA), e o modelo não intervencionista (Brasil e França). Enquanto os primeiros aplicam, desde a década de 1960, uma legislação rígida no combate à discriminação no mercado de trabalho, os últimos têm se recusado a fazê-lo, preferindo priorizar o modelo meritocrático de igualdade de oportunidades. Nos EUA, introduziram-se medidas de ação afirmativa no novo código do trabalho, adotado a partir de 1964. O modelo inglês se baseia em uma série de medidas inauguradas com o Race Relations Act, de 1965. Contudo, se a desigualdade racial é baixa no país bretão, isto se deve mais aos resultados alcançados com as minorias hindus e paquistanesas que com os negros. A França vive, por sua vez, uma fase de intenso debate sobre políticas de discriminação positiva. A legislação existente dificulta, contudo, a própria realização de estudos socioeconômicos de avaliação de desigualdades raciais, já que a variável étnico-racial não pode ser incluída nas estatísticas nacionais ${ }^{19}$. Na verdade, a diferença na abordagem do problema racial nestes países parece se dever em grande parte ao contexto histórico em que se dá o debate: as reivindicações dos movimentos sociais na Inglaterra e EUA se constituem em plena era keynesiana; na França e Brasil elas só surgiriam anos mais tarde, no período de desestruturação do Estado de bem-estar social.

Como forma de ilustrar a trajetória de dois casos paradigmáticos das relações raciais - Brasil e EUA - concebemos um gráfico comparativo de seus respectivos IHR ao longo dos últimos 100 anos. A evolução, tanto no Brasil, como nos EUA, entre princípios do século e a década de 1950, se deve em

\footnotetext{
${ }^{19}$ Há maneiras de contornar este problema, utilizando as informações sobre a população "de origem" estrangeira. Uma fonte importante são as estatísticas do FASILD (2005), que utilizamos em nossos cálculos.
} 
grande medida à urbanização e à proletarização do negro, que passa assim a se beneficiar de um leque de possibilidades mais diversificadas no mercado de trabalho. Como se vê, a situação no Brasil parecia no início ser de fato ligeiramente superior, no mesmo momento em que vigorava o regime de segregação no sul estadunidense. Em seguida, enquanto no Brasil o quadro de hierarquização racial fica praticamente estável desde os anos 1950, nos EUA há uma melhora significativa. $\mathrm{Na}$ conjuntura atual, os EUA se encontram em uma situação nitidamente superior à do Brasil, em termos de representatividade racial das elites, revertendo a situação que se observava nos anos 1950. Este resultado pode ser em grande parte atribuído às políticas de combate à discriminação, ou de ação afirmativa, colocadas em prática naquele país a partir de 1964, e, em particular, após o novo código do emprego de 1977. A partir de então as empresas devem contratar seus empregados de acordo com a representatividade racial da localidade onde se estabelecem, pagar salários iguais para trabalhadores brancos e não brancos igualmente produtivos, e interromper as práticas de discriminação na contratação e demissão de não brancos (em geral, os últimos a ser contratados mas os primeiros a ser demitidos $)^{20}$. O salto dado entre 1950 e 1985 em direção a uma elite mais igualitária em termos raciais é claramente refletido pelo indicador. Mais recentemente, nos últimos vinte anos, há, contudo, uma tendência de estabilidade nos EUA, em consequência possivelmente da flexibilização das leis de ação afirmativa. De qualquer maneira, o quadro nos EUA dos dias de hoje representa uma situação quase duas vezes superior ao caso brasileiro, cujo IHR de 2003 registrou queda de $8 \%$ em relação a 1982.

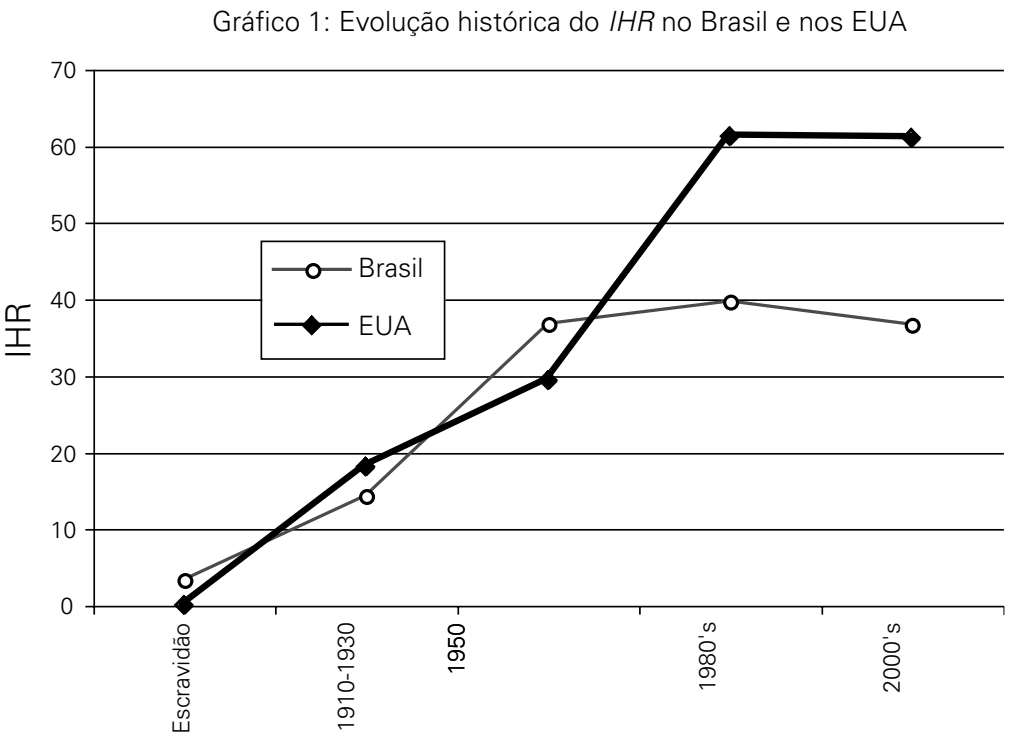

\footnotetext{
${ }^{20}$ Para uma história da implementaçãodas leis de ação afirmativa nos EUA, consultar, entre outros, Weiss (1997) e Bloom (1987).
} 
É interessante observar ainda como se comporta o indicador de hierarquização racial de um ponto de vista regional no Brasil, como mostra a tabela abaixo, onde destaca-se a posição distante de São Paulo em relação à média nacional:

Tabela 2: Índice de Hierarquização Racial em estados selecionados do Brasil, 2003.*

\begin{tabular}{l|c|c|c}
\hline Estado de residência & Elite branca & Elite não branca & IHR \\
\hline Rio de Janeiro & 21,6 & 6,3 & 29,2 \\
São Paulo & 19,0 & 5,8 & 30,5 \\
Minas Gerais & 15,2 & 5,4 & 35,5 \\
Alagoas & 13,5 & 3,6 & 26,7 \\
Bahia & 15,2 & 5,3 & 34,9 \\
Pernambuco & 14,3 & 5,7 & 39,9 \\
Ceará & 12,5 & 5,0 & 40,0 \\
Rio Grande do Sul & 14,1 & 4,6 & 32,6 \\
Paraná & 14,6 & 5,1 & 34,9 \\
Distrito Federal & 32,1 & 12,4 & 38,6 \\
\hline Total Brasil & 16,1 & 5,9 & 36,6 \\
\hline
\end{tabular}

Fonte: PNAD/IBGE 2003.

* O cálculo do índice tem como base trabalhadores em idade ativa.

Como qualquer outro indicador, este também está evidentemente sujeito a uma série de limites e imprecisões. Dentre eles, podemos citar a definição censitária de não brancos, variável entre países, ou ainda a oscilação no método de agrupamento das variáveis ocupacionais ao longo dos anos. Além disso, nenhum indicador substitui uma análise histórica, sociológica, demográfica, institucional e de economia política das relações sociais; ele apenas as complementa. Isto dito, acreditamos que o indicador aqui exposto traz uma informação adicional importante para a caracterização de um quadro de hierarquização racial no mercado de trabalho, pois pode permitir comparações internacionais e avaliar o resultado de políticas públicas de combate à discriminação ao longo do tempo.

\section{UMA MEDIDA DA DESIGUALDADE RACIAL DE RENDIMENTOS}

Usualmente, nos estudos empíricos da discriminação no mercado de trabalho, compara-se a renda média de não brancos à de brancos e toma-se esta relação como um indicador da desigualdade racial de rendimentos. Outros, conhecendo as desvantagens de se utilizar este indicador para avaliar a desigualdade, preferem utilizar a mediana da renda - mais apropriada, pois não 
está sujeita à influência de valores extremos da distribuição. Apesar dos limites deste indice de renda relativa ${ }^{21}$, a facilidade de manipulação lhe concede importantes atrativos. Vejamos, por meio do gráfico mais abaixo, como ele se apresenta para países como Brasil e EUA nas últimas duas décadas, e que ensinamentos podemos tirar de sua variação.

Parece claro que, no período em questão, a evolução relativa foi muito mais favorável aos negros e mestiços nos EUA que no Brasil. Saindo de um patamar semelhante no início dos anos 1980, quando os não brancos em ambos os países tinham uma renda próxima a $57 \%$ da dos brancos; nos dias de hoje, esta relação se elevou a $65 \%$ nos EUA, ficando praticamente estabilizada no Brasil. Vale notar também a tendência de queda registrada nos últimos três anos no país norte-americano, a primeira desde 1980.

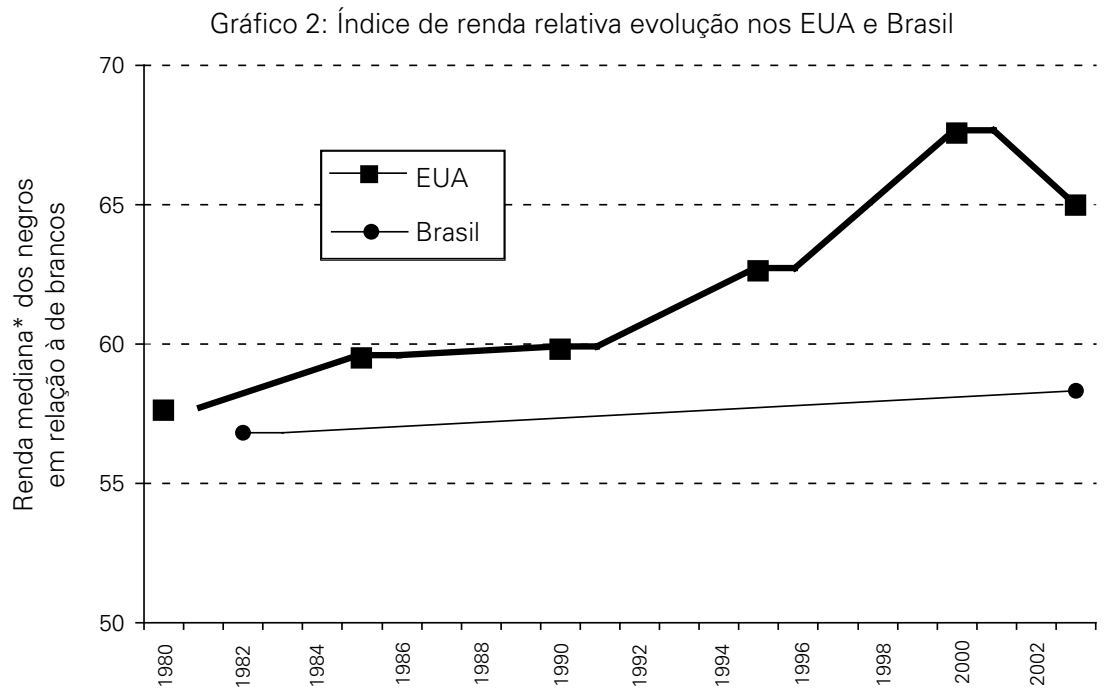

* Renda do chefe do domicílio Fontes: US Census Bureau e PNAD-IBGE

Por mais interessante e importante que possa ser esta comparação, ela deixa de lado informações fundamentais sobre a forma como se distribui a renda entre os grupos sociais em uma estrutura de rendimentos. Uma melhora no income ratio pode esconder uma apropriação relativa superior nos extratos mais altos de renda, enquanto que a situação na base da pirâmide tenha ficado estável.

Por esta razão, a maneira mais correta de se evidenciar o grau de desigualdade entre grupos populacionais é analisar se há diferenças em sua apropriação em todas as classes de rendimentos existentes. Sabemos que a renda no Brasil é extremamente concentrada, apesar da ligeira queda nos indicadores de desigualdade desde o final do período hiperinflacionário. Para explicitar empi-

${ }^{21}$ Income ratio, em inglês. Tem sido traduzido na literatura por "razão da renda". 
ricamente esta concentração, costuma-se observar como se distribui a população entre os decis de renda. Em 2003, por exemplo, vemos que os 30\% mais pobres da população têm renda inferior a $\mathrm{R} \$ 240$ (o salário mínimo à época). Ora, esta situação é bastante desigual conforme a cor da pele do trabalhador. Assim, nesta mesma faixa da distribuição, a proporção de brancos é de $21 \%$ e a de não brancos, $40 \%$. Há uma tendência, portanto, na base da pirâmide de rendimentos, de pobreza mais acentuada entre os negros e mestiços. Por outro lado, se tomarmos os dois últimos decis de nossa distribuição (rendimentos acima de R \$ 1.420), encontramos que $15 \%$ dos brancos estão nesta faixa de renda, enquanto que entre os não brancos este percentual não chega a atingir $5 \%$ (ver mais abaixo a Tabela 3 ).

Consequentemente, além de uma elevada taxa de concentração de renda na população brasileira em geral, parece evidente que esta renda se distribui de forma bastante desigual entre brancos e não brancos. Porém, como poderíamos medir esta desigualdade racial de rendimentos?

Uma maneira de ilustrar a concentração de uma variável qualquer é por meio da chamada curva de Lorenz, que compara os decis de distribuição em um dado momento a uma situação ideal na qual cada faixa de população recebe uma proporção equivalente da renda gerada na economia. Nossa proposta consiste em adaptar esta metodologia para estimar a desigualdade racial de rendimentos. Assim, o primeiro passo é comparar, graficamente, a distribuição cruzada de brancos e não brancos, o que nos dá a curva adaptada de Lorenz do gráfico abaixo.

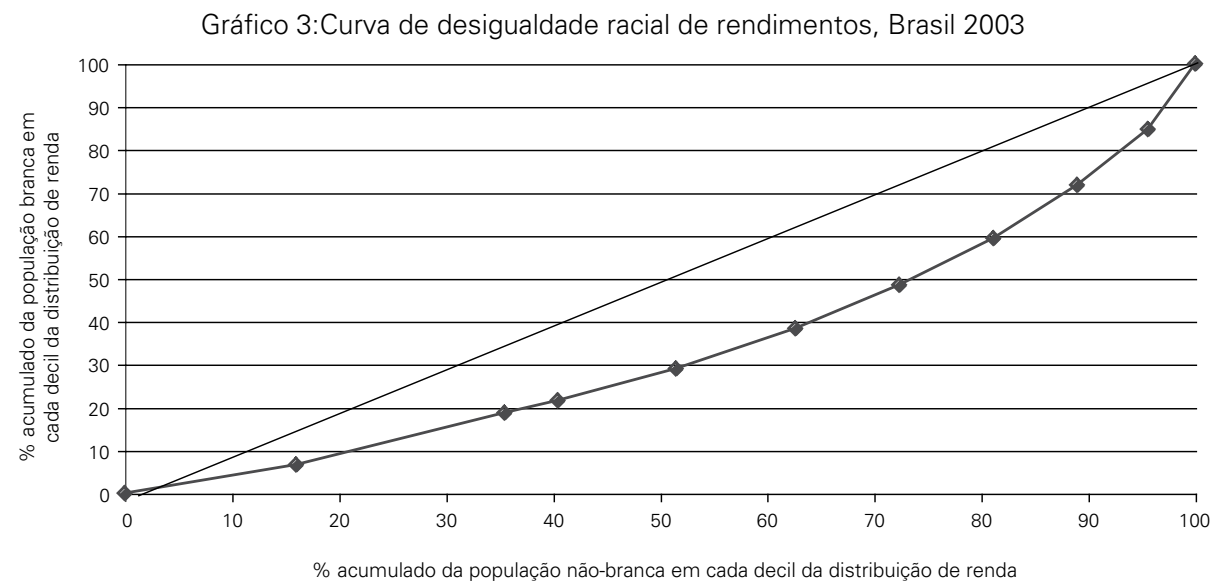

Fonte: PNAD-IBGE.

Os pontos na curva acima trazem as proporções acumuladas de brancos (eixo Y) em comparação às proporções acumuladas de não brancos (eixo X) para cada um dos dez decis da distribuição de renda da população brasileira. A diagonal traçada representa uma situação ideal na qual, para cada decil, a 
proporção de não brancos é equivalente à proporção de brancos, representando, portanto, uma linha de perfeita igualdade racial de distribuição de renda. Nesta situação, na qual a distribuição dos não brancos se equipara à distribuição existente dos brancos, veríamos, por exemplo, no primeiro decil uma proporção de não brancos cair para $6,59 \%$, no segundo para $18,69 \%$, e assim consecutivamente (ver Tabela 3$)^{22}$.

Estamos diante, portanto, de um quadro clássico de desigualdade de rendimentos em uma dada estrutura de distribuição. A apropriação que se faz da renda nacional beneficia muito mais aos brancos que aos não brancos, como se vê no Gráfico 3 acima. Assim, uma proporção muito superior de não brancos termina concentrando-se nos segmentos de mais baixa renda, ao passo que, nos segmentos de mais alta renda, a situação se inverte: há uma quantidade de brancos em proporção relativamente muito superior à de não brancos.

Tendo estes elementos em mente, podemos passar ao cálculo propriamente dito de nosso indicador. A lógica de cálculo é a mesma dos coeficientes de concentração, como o de Ginii ${ }^{23}$. Assim, o que nos interessa é medir a distância da curva de nossos pontos de distribuição cruzada em relação à reta de igualdade perfeita. Em outras palavras: quanto maior a área delimitada entre a reta de igualdade e a curva desenhada pelos pontos da distribuição, pior a situação de desigualdade racial. O valor da área descrita por esta figura nos dará um indicador de desigualdade de rendimentos ente brancos e não brancos ${ }^{24}$.

Tabela 3: Proporção de brancos e não brancos em decis da distribuição de renda e cálculo do coeficiente de desigualdade racial Brasil, 2003

\begin{tabular}{ccccc}
\hline Decis & Renda (R\$) & $\begin{array}{c}\text { \% Acum. de } \\
\text { Brancos }\end{array}$ & $\begin{array}{c}\text { \% Acum. de } \\
\text { Não Brancos }\end{array}$ & Área \\
\hline 10 & 100 & 6,59 & 16,01 & 52,71 \\
20 & 205 & 18,69 & 35,50 & 246,28 \\
30 & 240 & 21,65 & 40,47 & 100,40 \\
40 & 260 & 28,98 & 51,48 & 278,74 \\
50 & 340 & 38,41 & 62,66 & 376,67 \\
60 & 430 & 48,53 & 72,35 & 420,99 \\
70 & 550 & 59,29 & 81,17 & 475,54 \\
\hline
\end{tabular}

\footnotetext{
${ }^{22}$ Isto significa que, em nossa concepção, fazemos abstração da desigualdade de rendimentos inerente à distribuição, e nos concentramos unicamente na desigualdade racial de uma dada distribuição.

${ }^{23} \mathrm{E}$, tal como o coeficiente de Gini, o indicador que propomos exclui os chefes de família sem rendimentos, o que, para efeito de nossas estimativas, está, muito provavelmente, subestimando o quadro de desigualdade racial.

${ }^{24} \mathrm{O}$ procedimento de cálculo que adotamos para chegar a este valor é bastante simples. Basta calcular as áreas existentes entre cada ponto da distribuição e o eixo $\mathrm{X}$ do gráfico. Em seguida, diminuir a soma destas áreas da área total abaixo da diagonal traçada (5000), e dividir o valor encontrado por 5000.
} 


\begin{tabular}{ccccc}
\hline 80 & 800 & 71,68 & 88,96 & 510,51 \\
90 & 1420 & 84,68 & 95,58 & 517,64 \\
100 & 51750 & 100,00 & 100,00 & 407,91 \\
\hline \multicolumn{4}{r}{ Soma das áreas abaixo da curva Lorenz } & 3387,39 \\
& Área total abaixo da reta de perfeita igualdade & 5000,00 \\
& Área entre a reta e a curva de distribuição & 1612,61 \\
& Coeficiente de desigualdade racial & 32,3 \\
\hline
\end{tabular}

Fonte: PNAD/IBGE, 2003. Renda do chefe de família.

$O$ índice que encontramos para o coeficiente de desigualdade racial (CDR) no Brasil em 2003 é de 32,3. Isto indica que há um longo caminho ainda a se percorrer para atingir a igualdade racial perfeita em termos de rendimentos no país (dada por um CDR igual a zero). Calculando os mesmos valores para homens e mulheres no mesmo período no Brasil, chegamos a um índice de 18,6; o que comprova a manutenção de desigualdades sexuais de rendimentos, mas mostra, também, que as desigualdades raciais encontram-se atualmente em um nível bem mais elevado que as de gênero. Além disso, nos últimos vinte anos, houve uma piora no quadro de desigualdade racial de rendimentos, já que, em 1982, encontramos um CDR de 31,3, abaixo portanto do nível atual.

Outro elemento que ajuda a caracterizar o quadro de desigualdade racial de rendimentos no Brasil é comparar com a situação em países nos quais há políticas públicas para tentar corrigir o problema. Calculamos, utilizando dados do censo daquele país, o CDR dos EUA para períodos mais ou menos equivalentes a nossas estimativas no Brasil. $\mathrm{O}$ resultado indica uma clara tendência de redução na desigualdade nos últimos vinte anos. E mais: o coeficiente parte de um nível próximo ao do Brasil no início dos anos 1980 (de 31,0), no período em que se começam a aplicar as medidas de ação afirmativa no mercado de trabalho. Porém, quase 25 anos depois, a situação se inverte: enquanto o Brasil exibiu uma piora no coeficiente, os EUA sinalizam uma evolução, reduzindo o CDR para 25,2:

Tabela 4: Proporção de brancos e não brancos em decis da distribuição de renda e cálculo do coeficiente de desigualdade racial EUA 2003

\begin{tabular}{cccc}
\hline $\begin{array}{c}\text { Faixas de Renda } \\
\text { (US\$)* }\end{array}$ & $\begin{array}{c}\text { \% Acum. de } \\
\text { Brancos }\end{array}$ & $\begin{array}{c}\text { \% Acum. de } \\
\text { Não Brancos }\end{array}$ & Área \\
\hline até 15000 & 14,2 & 27,4 & 194,54 \\
25000 & 27,0 & 43,4 & 329,60 \\
35000 & 38,8 & 56,7 & 437,57 \\
50000 & 53,8 & 71,7 & 694,50 \\
75000 & 72,3 & 86,3 & 920,53 \\
\hline
\end{tabular}




\begin{tabular}{rccc}
\hline 100000 & 83,8 & 93,3 & 546,35 \\
+ de 100000 & 100,0 & 100,0 & 615,73 \\
\hline & Soma das áreas abaixo da curva Lorenz & $\mathbf{3 7 3 8 , 8 2}$ \\
& Área total abaixo da reta de perfeita igualdade & 5000,00 \\
& Área entre a reta e a curva de distribuição & 1261,18 \\
& Coeficiente de desigualdade racial & $\mathbf{2 5 , 2}$ \\
\hline
\end{tabular}

Fonte: U.S. Census Bureau, Statiscal Abstract, 2006. Renda do Chefe de Família.

\section{CONCLUSÕES}

Apesar da profusão de estudos empíricos sobre as desigualdades raciais no Brasil, a enorme quantidade de dados relativos ao nível e à evolução da situação parece atuar mais no sentido de confundir do que de informar a respeito da verdadeira magnitude fenômeno. As tentativas feitas no sentido de produzir indicadores de desigualdade racial enfrentaram, além disso, uma série de limites. Com relação à desigualdade racial na estrutura ocupacional, conforme mostramos, a técnica hoje existente não é capaz de resolver o problema de agregação e de ordenamento das diferentes profissões no mercado de trabalho. A alternativa que sugerimos, o índice de hierarquização racial, ao focar unicamente na incorporação de não brancos na elite ocupacional, trouxe ao menos uma vantagem em relação ao índice de dissimilaridade e seus derivados, ao gerar resultados diretamente comparáveis. Já no que se refere ao coeficiente de desigualdade racial, o indicador, de um ponto de vista técnico, é superior às medidas normalmente utilizadas, como o income ratio e os indicadores normativos utilizados pelos autores de tradição neoclássica. Partindo da lógica de cálculo dos indicadores de concentração, como o coeficiente de Gini, nosso indicador de desigualdade racial de rendimentos permite a agregação das variáveis e é de fácil manipulação.

Do ponto de vista teórico, confirmamos que tanto a hierarquização racial, quanto a desigualdade racial de rendimentos, pioraram nos últimos vinte anos no Brasil, período que corresponde à aceleração das políticas econômicas de cunho liberal. A construção e a utilização de índices não substituem, evidentemente, uma análise descritiva e histórica detalhada dos fenômenos econômicos; contudo, sua utilização em nossa investigação se mostrou capaz de resolver alguns impasses na análise das desigualdades raciais, ao fornecer um indicador sintético da situação.

Destacaríamos, para terminar, alguns aspectos normativos de nossos resultados. O índices que desenvolvemos demonstram claramente que no Brasil de hoje persiste um nível importante de desigualdade racial, não muito distante do que havia nos EUA ao final do período segregacionista nos anos 1950, por exemplo. Em termos dinâmicos, observou-se uma tendência à piora na 
hierarquização racial e na desigualdade racial de rendimentos. Ao contrário, portanto, do que prevê o paradigma dominante na Economia, a liberalização comercial, a desregulamentação do mercado, a flexibilização do trabalho, diretrizes centrais do programa econômico seguido pelo Brasil no período recente, não têm sido capazes de promover uma maior integração de negros e mestiços na elite, nem de diminuir a distância que os separa dos brancos na remuneração do trabalho. Com base nisto, somos levados a afirmar que apenas uma intervenção no funcionamento do mercado de trabalho, à luz das políticas aplicadas em países como os EUA e a GB, no sentido de interromper a atuação de mecanismos de discriminação, será capaz, hoje, de diminuir a distância que separa negros e mestiços de brancos na estrutura de classes e de rendimentos na economia brasileira.

\section{REFERÊNCIAS BIBLIOGRÁFICAS}

ARROW, Keneth (1972) “Models of job discrimination”, in: A. H. Pascal (ed.), Racial Discrimination in Economic Life, Lexington: D. C. Heath.

BALIBAR, Etienne e WALLERSTEIN, Immanuel (1988) Race, Nation et Classe. Les Identités Ambiguës, Paris: La Découverte.

BASTIDE, Roger e FERNANDES, Florestan (1955) Relações Raciais entre Brancos e Negros em São Paulo, São Paulo: Anhembi.

BECKER, Gary ([1957] 1971) The Economics of Discrimination, Chicago: The University of Chicago Press.

BLOOM, Jack M. (1987) Class, Race and the Civil Rights Movement, Indianapolis: Indiana University Press.

CAMPANANTE, Felipe et al. (2004) "Desigualdade salarial entre raças no mercado de trabalho urbano brasileiro: aspectos regionais", Revista Brasileira de Economia, v. 58 (2): 185-210.

CARLSON, Susan (1992) “Trends in race/sex occupational inequality: conceptual and measurement issues", Social Problems, v. 39 (3): 268-290.

CAVALIERI, Claudia e FERNANDES, Reynaldo (1998), "Diferenciais de salários por gênero e cor: uma comparação entre as regiões metropolitanas brasileiras”, Revista de Economia Politica, vol. 18 (69): 158-175.

CONRAD, Cecilia (1993) "A different approach to the measurement of income inequality", Review of Black Political Economy, v. 22 (1): 19-31.

COWELL, Frank e JENKINS, Stephen P. (1995) "How much inequality can we explain? A methodology and an application to the United States", The Economic Journal, v. 105 (429): 421-430.

DARITY JR., William e DESHPANDE, Ashwini (2000) “Tracing the divide: intergroup disparity across countries", Eastern Economic Journal, v. 26 (1): 75-85.

DOS SANTOS, Luís (1998) “Espaço negro e espaço branco na estrutura de ocupações”, in: Castro, Nadya e Barreto, Vanda, Trabalho e desigualdades raciais. Negros e brancos no mercado de trabalho de Salvador, Annablume, São Paulo.

DESTREMEAU, Blandine e SALAMA, Pierre (2002), Mesures et Démesure de la Pauvreté, Paris: Presses Universitaires de France.

DU BOIS, W. E. ([1899] 1975) The Philadelphia Negro, Millwood: Kraus-Thomson Organization Limited.

FASILD (Fonds d'action et de soutien pour l'intégration et la lutte contre le discrimination) (2005) Jeunes diplômés issus de l'immigration: insertion professionnelle ou discriminations?, Paris: La Documentation Française. 
FERNANDES, Florestan (1972) O Negro no Mundo dos Brancos, São Paulo: Difusão Europeia do Livro.

FOSSET, Mark (1986) "Racial occupational inequality, 1940-1980: national and regional trends", American Sociological Review, v. 51 (3): 421-429.

FREYRE, Gilberto ([1933]2003) Casa Grande e Senzala, São Paulo: Global Editora.

GORENDER, Jacob (1991) A Escravidão Reabilitada, São Paulo: Editora Ática.

GORENDER, Jacob (2000) Brasil em Preto e Branco, São Paulo: Editora Senac.

GOUVERNEUR, Jaques (1998) Découvrir L'économie. Phénomènes Visibles et Réalités Cachées, Paris: Éditions Sociales.

HASENBALG, Carlos (1979) Discriminação e Desigualdades Raciais no Brasil, Rio de Janeiro: Graal.

HENRIQUES, Ricardo (2001) "Desigualdade racial no Brasil: evolução das condições de vida na década de 90", IPEA, Texto para discussão, n. 807.

LAFARGUE, Paul ([1883] 2004) Le Droit à la Paresse, Paris; Éditions Allia.

LEIMAN, Melvin M. (1993) The Political Economy of Racism. A History, Londres: Pluto Press.

LOVELL, Peggy (2000) "Race, gender and regional labour market inequalities in Brazil", Review of social economy, v. 58 (3): 277-293.

MYRDAL, Gunnar (1942) An American Dilemma. The Negro Problem and Modern Democracy, New York: Happer \& Brothers Publishers.

OLIVEIRA, Ana Maria e MIRANDA-RIBEIRO, Paula (1998) "Diferenciais ocupacionais por raça e gênero no mercado de trabalho metropolitano no Brasil", XI Encontro Nacional de Estudos Populacionais, APEB.

PAES DE BARROS, Ricardo e MENDONÇA, Rosana (1996) "Diferenças entre discriminação racial e por gênero e o desenho de políticas antidiscriminatórias", Estudos Feministas, n. 1: 183-193.

PAIXÃO, Marcelo (2004) "An account of the (precarious) social situation of the African descendant population in contemporary Brazil”, Journal of Black Studies, v. 34 (6): 743-765.

PHELPS, Edmund (1972) "The statistical theory of racism and sexism", The American Economic Review, n. 4, v. 62 .

PNUD (Programa das Nações Unidas para o Desenvolvimento) (2005) Atlas Racial do Brasil.

RAY, Debraj (1998) Development Economics, Princeton: Princeton University Press.

REIS, Maurício C. e CRESPO, Ana R. (2005) "Racial discrimination in Brazil: an analysis of the age, period and cohort effects", IPEA, Texto para Discussão, n. 1114.

SEN, Amartya (1997) On Economic Inequality, Oxford: Clarendon Press.

SEN, Amartya (1999) Repenser l'inégalité, Paris: Seuil.

SILBER, Jaques (ed.) (1999) Handbook on Income Inequality Measurement, Boston: Kluwer Academic Publishers.

TELLES, Edward (1992) "Residential segregation by skin color in Brazil”, American Sociological Review, v. 57 (2): 186-197.

TELLES, Edward (2003) Racismo à Brasileira. Uma Nova Perspectiva Sociológica, Rio de Janeiro: Relume Dumará.

VERBURG, Rudi (2000) "Adam Smith's growing concern on the issue of distributive justice”, The European Journal of the History of Economic Thought, v. 7 (1): 23-44.

WEISS, Robert J. (1997), We Want Jobs. A History of Affirmative Action, New York: Routledge.

WELCH, Finis (1967) "Labor-market discrimination: an interpretation of income differences in the rural South", The Journal of Political Economy, v. 75 (3): 225-240. 